\title{
La protección internacional de los Derechos Humanos y la soberanía nacional
}

Mara Gómez Pérez

\section{Nota introductoria}

El desarrollo de los sistemas de protección de los derechos humanos está estrechamente relacionado con el establecimiento del Estado de derecho. Una administración pública elegida democráticamente, sujeta al ordenamiento constitucional que libremente haya dictado el pueblo a través de sus legisladores, junto con la existencia de una justicia independiente, son garantías fundamentales de un régimen justo.

Sin embargo, la ingenua creencia del siglo XVIII y primera mitad del XIX de que era suficiente consagrar los derechos humanos en los textos constitucionales de las naciones para que fuesen respetados por las autoridades y los propios ciudadanos, ha caído junto con el desbordamiento constante de los poderes públicos ${ }^{1}$. La realidad ha dado múltiples ejemplos que demuestran que la Constitución ya no es suficiente para garantizar la libertad, la justicia y el bienestar de los ciudadanos².

De ahí precisamente surge la necesidad de instrumentar la protección internacional de los derechos humanos y de las libertades fundamentales, pues la sumisión del Estado a todos los sistemas de protección de derechos humanos, ya sean nacionales, regionales o universales, hoy día constituye la manera más sólida, y en algunos casos la única, de

1 Héctor Fix-Zamudio, Protección Juridica de los Derechos Humanos. Estudios Comparativos, CNDH, México 1999, p. 26.

2 Felix Laviña, Sistemas Internacionales de Protección de los Derechos Humanos, Ed. Palma, Buenos Aires 1987, p. 2. 
asegurar el efectivo reconocimiento y respeto de la dignidad de la persona humana ${ }^{3}$.

\section{Universalismo y regionalismo en la protección internacional de los derechos humanos}

Durante los siglos XIX y XX se operó un proceso lento pero progresivo hacia la internacionalización de la protección de los derechos humanos que se intensificó sobre todo después de la segunda guerra mundial.

El derecho internacional público estableció como uno de sus fines esenciales la protección de los derechos humanos y paso a paso, desde la proscripción de la trata de esclavos por los tratados de Viena de 1815, hasta la Carta de las Naciones Unidas y la Declaración Universal de los Derechos del Hombre aprobada por la Asamblea General de la ONU el 10 de diciembre de 1948, fue consagrando una legislación internacional progresista y progresiva que ha ido otorgando cada vez más y mejores sistemas de protección de estos derechos.

Esta protección se ha ido dando a través de esquemas tanto universales como regionales. Así, la Declaración Universal de los Derechos Humanos constituye un instrumento de tipo universal en el sistema de las Naciones Unidas que, si bien no es un tratado sino una resolución de la Asamblea General, es una fuente de derecho y constituye el fundamento esencial de todo el sistema de la ONU en esta materia.

Predominantemente y además de esta Declaración Universal, el sistema universal se integra por el Pacto de Derechos Económicos, Sociales y Culturales, el Pacto de Derechos Civiles y Políticos (ambos de diciembre de 1996) y el Protocolo Facultativo al Pacto de Derechos Civiles y Políticos, legislación internacional que, además, ha creado órganos de protección de los derechos humanos y procedimientos especiales para ello.

Pero, a su vez, se han creado sistemas regionales como el de Europa, cuyo origen se cifra en la Convención de 1950, desarrollada a través de varios protocolos adicionales, y el sistema regional americano, que

3 Cfr. Héctor Gros Spiell, "La Protección Internacional de los Derechos Humanos y la Eficacia de las Estructuras de Protección en el Ámbito Regional Americano", en: Revista de la Facultad de Derecho de la Universidad de Granada, № 4, 1984. 
comprende a todos los países que son parte en la Carta de la Organización de Estados Americanos y de la Convención Americana de Derechos Humanos de San José de Costa Rica.

La coexistencia de sistemas regionales y universales de protección de los derechos humanos nos lleva al estudio de la cuestión del universalismo y el regionalismo en la materia. Al respecto, coincidimos con la doctrina dominante ${ }^{4}$ en el sentido de que no son fórmulas antitéticas ni excluyentes, y que, en la medida de lo posible, deben adecuarse para sumar sus ventajas con el fin de obtener un mejor resultado en función de la defensa de los derechos y libertades del ser humano.

Sobre el tema, la doctrina ha analizado la interacción del universalismo y el regionalismo en la creación de las normas internacionales, observando que tanto los textos universales han influido en los regionales, como éstos en aquéllos. Merece aquí anotarse que la Declaración Americana de 1948 antecedió en unos siete meses a la Declaración Universal de los Derechos Humanos 5 .

De igual manera, se han estudiado las consecuencias de la coexistencia de dichos sistemas y sus respectivos órganos. A este respecto se entiende que la previa consideración de un determinado caso en el sistema regional no debe impedir la acción del sistema universal, y a la inversa, la investigación iniciada en el sistema universal, no impide la acción del regional, e incluso, se estima que es perfectamente admisible la intercomunicación de informaciones y resultados entre los órganos de uno y otro sistema. No obstante, tratándose de procedimientos ya iniciados, los diversos tratados sí han pretendido impedir la existencia de dos o más procedimientos sobre el mismo caso y, con ello, la posible emisión de resoluciones contradictorias, señalando expresamente que una demanda sólo será admitida cuando el asunto no haya sido sometido a otra instancia internacional, ya sea regional o universal.

4 Félix Laviña, op.cit., p. 11.

5 Thomas Buergenthal, Robert E. Norris y Dinah Shelton, La Protección de los Derechos Humanos en las Américas, Civitas/IIDH, Madrid 1990, p. 34; y Jorge Madrazo, Derechos Humanos: El Nuevo Enfoque Mexicano, FCE, México 1993, p. 24. 


\section{México y la protección de los derechos humanos. Los orígenes de la Comisión y de la Corte Interamericana de Derechos Humanos}

Si bien México ha mostrado una marcada proclividad a la tutela de los derechos humanos como lo demuestra el establecimiento en la Constitución de las garantías individuales y políticas, su avanzada legislación en materia de derechos sociales, la instauración y difusión internacional del juicio de amparo, la reciente creación de otros medios de control constitucional y su perfeccionamiento jurisprudencial, y la subscripción de múltiples y muy diversos instrumentos internacionales que establecen catálogos y crean sistemas alternos de protección de esos derechos, lo cierto es que también en ciertos momentos se ha mostrado receloso a este respecto ${ }^{6}$.

Las experiencias negativas de América Latina en la Sociedad de Naciones provocaron cierta desconfianza en los sistemas universales y en un principio, nuestro país optó por pugnar por una declaración regional, convencido de que en un ámbito territorial más estrecho podían obtenerse documentos más acordes con la realidad del continente ${ }^{7}$.

En el siglo XX, incluso antes de la Segunda Guerra Mundial, la preocupación regional por los derechos humanos se expresó mediante la subscripción de convenciones en materia de derechos de los extranjeros, nacionalidad y asilo, derechos de la mujer, condiciones de los trabajadores, protección a la niñez, etcétera ${ }^{8}$.

No obstante, el gobierno mexicano fue controlando paulatinamente su ímpetu inicial y sus criterios respecto a un sistema regional de protección de los derechos del hombre, porque conceptuaba que ello iba en contra del Principio de la no Intervención que ha sido una de las normas fundamentales de las relaciones internacionales de México. Ello también explica que, posteriormente, México haya abogado sólo por una declaración de derechos humanos y no por un mecanismo intergubernamental de tutela de estos derechos.

Como sea, hacia el año de 1959 se creó la Comisión Interamericana de Derechos Humanos. Y no deja de sorprender porque, como se señalaba, el concepto de la no intervención estaba fuertemente arraigado, y

6 César Sepúlveda, "México, la Comisión Interamericana y la Convención Americana sobre Derechos Humanos", en: La Protección Internacional de los Derechos del Hombre. Balances y Perspectivas, UNAM, México 1983, p. 191 y ss.

7 Idem.

8 Thomas Buergenthal, et al, op. cit., p. 33. 
un cuerpo de esta naturaleza no dejaba de significar un posible escrutinio de los asuntos domésticos que el nacionalismo de los países americanos reserva exclusivamente al dominio interno.

Muy probablemente influyó que para entonces, ya habían madurado muchas nociones sobre la tutela internacional de los derechos de la persona humana y se había observado que el funcionamiento de la Comisión de Derechos Humanos de las Naciones Unidas no había suscitado mayores problemas, además de que ya había ganado terreno la idea de que la transgresión de los derechos humanos en un país no sólo afecta a éste, sino que constituye un factor de alteración de la paz en toda la región.

$\mathrm{Si}$ bien en un inicio la Comisión Interamericana de Derechos $\mathrm{Hu}-$ manos fue concebida como un órgano con funciones que podríamos calificar de inocuas o anodinas (estimular la conciencia de los derechos humanos en América Latina, preparar estudios o informes sobre el desempeño de sus funciones, servir de cuerpo consultivo de la OEA en materia de derechos humanos, etc.), curiosamente su buen desempeño, sobre todo en ciertos conflictos clave de la región, demostró pronto que se le había puesto un cerco demasiado estrecho.

Así, entre 1965 y 1967 (primero en la Conferencia Extraordinaria de Río de Janeiro y luego en el Protocolo de Buenos Aires) se reexaminó el papel y las funciones de la Comisión y se le confirieron nuevas y más importantes atribuciones, y casi inmediatamente después, en el año de 1969, se creó la Corte Interamericana de Derechos Humanos, órgano de fundamental importancia en nuestros días, en tanto que tiene competencia contenciosa, esto es, para decidir casos en los que se alega la violación por un Estado miembro de los derechos humanos protegidos por la Convención Americana sobre Derechos Humanos, además de competencia consultiva, la que le autoriza interpretar esta Convención y otros instrumentos de derechos humanos a petición de los Estados miembros de la OEA o de algunos órganos de la misma ${ }^{9}$.

\section{La Convención Americana de Derechos Humanos}

Esta Convención fue aprobada en 1969 durante la conferencia intergubernamental convocada por la OEA que se celebró en San José

$9 \quad$ Ibidem, pp. 54 y 55. 
de Costa Rica, por lo que también se le conoce como "Pacto de San José». No obstante, entró en vigor hasta 1978, después de recibirse el depósito del instrumento de ratificación número once en términos de su artículo 74.2.

La Convención Americana es más extensa que la mayoría de los instrumentos internacionales de derechos humanos. Contiene 82 artículos y codifica más de dos docenas de derechos que incluyen: el derecho al reconocimiento de la personalidad jurídica, a la vida, a la integridad personal, a la libertad personal, a las garantías judiciales, a la privacidad, al nombre, a la nacionalidad, a participar en el gobierno, a la igualdad ante la ley y a la protección judicial. Asimismo, proscribe la esclavitud y proclama la libertad de conciencia y de religión, de pensamiento y de expresión, así como la libertad de reunión, asociación, circulación y de resistencia, además de prohibir la aplicación retroactiva de las leyes y de las sanciones penales.

Los Estados parte se comprometen a respetar y garantizar el libre y pleno ejercicio de estos derechos a toda persona que esté sujeta a su jurisdicción, por lo que bien puede afirmarse que tienen tanto deberes positivos como negativos. Por un lado, tienen la obligación de no violar los derechos de los seres humanos ( $v r . g r$. no torturar a una persona) pero las obligaciones de los Estados se extienden más allá de este deber negativo, de tal forma que también se le puede exigir a las autoridades internas la adopción de las medidas positivas necesarias y razonables, según las circunstancias, que garanticen el pleno ejercicio de los derechos reconocidos por la Convención (por ejemplo, garantizar la no tortura de sus nacionales aun cuando dicha tortura no sea llevada a cabo por agentes públicos).

Se ha dicho que los derechos que la Convención Americana proclama son tantos y de tal magnitud (incluso mayores que los contenidos en la Convención Europea o el Pacto de Derechos Civiles y Políricos) que puede dudarse que exista algún país en América que cumpla con todos ellos $^{10}$. Este hecho, sin embargo, no impidió que la Convención obtuviese el número necesario de ratificaciones para entrar en vigor y, más aún, que curiosamente la mayoría de dichas ratificaciones no contuviesen ninguna reserva, pese a que las condiciones jurídicas y fácticas de por lo menos algunos países ratificantes, tal vez debieron haber dado lugar a un mayor número de reservas. 
Por último, vale la pena remarcar que la Convención Americana establece dos órganos para asegurar su cumplimento, la Comisión Interamericana de Derechos Humanos y la Corte Interamericana de Derechos Humanos, cada uno compuesto por siete expertos en materia de derechos humanos, elegidos a título personal y no como representantes gubernamentales. Las normas que regulan el funcionamiento de la Corte están contenidas en tres instrumentos que son, en orden jerárquico: la Convención, el Estatuto de la Corte y el Reglamento expedido por los propios miembros de la Corte.

\section{Las relaciones entre el derecho interno y el derecho internacional}

El derecho interno debe velar por la observancia de los derechos humanos excluyendo la razón de Estado. A su vez, el derecho internacional debe actuar eficazmente protegiendo dichos derechos fuera de las soberanías nacionales ${ }^{11}$. Estas expresiones, lógicas en sí mismas, adquieren un valor paradójico cuando las normas de cada uno de estos sistemas se contraponen o de alguna manera entran en contradicción.

En nuestro país, la Constitución mexicana es la norma de normas. Impone deberes, crea limitaciones, otorga facultades y concede derechos. Nada ni nadie puede estar sobre ella, pues su naturaleza de suprema niega la posibilidad de que esté sometida a otro cuerpo normativo superior $y$, en cambio, requiere que todo le sea inferior y que cada acto de autoridad esté de acuerdo con ella. Toda la estructura normativa del país descansa sobre esta idea.

El principio que determina la superioridad de nuestra Constitución se puede constatar de muy diversas maneras. Por un lado, los artículos $40^{\circ}$ y $133^{\circ}$ le otorgan la cualidad de «ley fundamental» y de «Ley Suprema de la toda la Unión». Esta supremacía se evidencia también en el término que se utiliza para denominarla: Constitución; es decir, lo que constituye, lo que funda, crea o establece, lo que organiza, faculta o limita. Pero además y muy especialmente, su supremacía deriva de las garantías de cumplimiento, pervivencia y defensa de la Constitución que consagra este mismo cuerpo normativo, verbi gratia: la protesta de

I 1 Juan Antonio Travieso, Derechos Humanos y Derecho Internacional, Editorial Heliasta, Buenos Aires 1996, p. 28. 
los funcionarios públicos, el procedimiento investigatorio de la Suprema Corte de Justicia, el juicio de amparo, las controversias constitucionales y las acciones de inconstitucionalidad, el juicio político, los principios relativos a la inviolabilidad de la Constitución, etcétera ${ }^{12}$.

En nuestro derecho, ella es la norma de normas; la que da validez y coherencia a todo el orden jurídico, la norma que organiza cada uno de los componentes de ese orden y los jerarquiza a fin de que puedan aplicarse e interpretarse de una manera armónica y funcional. En ese sentido, cualquier otra norma, ya sea internacional o bien nacional, siempre estará subordinada a la Constitución.

Estos principios, consagrados no sólo en nuestra Constitución sino en la de muchos otros países, encuentran una franca oposición al contrastarlos con los tratados internacionales y, en especial, con aquéllos relativos a la materia de derechos humanos.

Conviene precisar aquí que la doctrina internacionalista encuentra en el derecho comparado cuatro tipos de jerarquía o interrelación entre los tratados internacionales sobre derechos humanos y el derecho interno:

1. Supraconstitucional: en la cual los tratados sobre derechos humanos, por disposición expresa de la propia Constitución, tienen una jerarquía superior a ella. Este es el sistema que rige en Holanda.

2. Constitucional: en donde también por disposición expresa de la Constitución, los tratados sobre derechos humanos tienen una jerarquía exactamente igual a la de la propia Constitución. Este método funciona en Argentina y en 1999 fue introducido en la nueva Constitución Bolivariana de Venezuela.

En los dos sistemas antes apuntados, los tratados internacionales sobre materias diversas a los derechos humanos tienen una jerarquía inferior a la Constitución.

3. Supralegal: en el que los tratados internacionales sobre derechos humanos o, incluso, sobre cualquier otra materia, se colocan por debajo de la Constitución pero por encima de las leyes internas. Este sistema rige en Colombia y, aunque no de manera totalmente definida, también en México ${ }^{13} ; y$

12 Para mayor información sobre el tema ver: Guillermo I. Ortiz Mayagoitia, " $G a-$ rantías de Cumplimento, Defensa y Pervivencia de la Constitución", artículo inédito.

13 Por muchos años se sostuvo en México que las leyes federales y los tratados 
4. Legal: En donde los tratados internacionales, sean de la materia que sea, tienen un rango inferior a la Constitución e idéntico a una ley interna. Este es el sistema que todavía se sigue en la mayoría de las naciones.

Empero, para el derecho internacional la jerarquía interna de un tratado o su adecuación con las normas internas, es prácticamente irrelevante.

De conformidad con los artículos $26^{\circ}, 27^{\circ}$ y $46^{\circ}$ de la Convención de Viena sobre el Derecho de los Tratados del 23 de mayo de 1969, todo tratado en vigor obliga a las partes y debe ser cumplido por ellas de buena fe y, por ello mismo, un Estado no puede invocar las disposiciones de su derecho interno como justificación del incumplimiento de un tratado, salvo en lo relativo a las normas concernientes a la competencia para celebrar los tratados, pero de una manera muy restringida.

En efecto, una vez que un tratado internacional es propalado en el ámbito internacional y en tanto éste se encuentre en vigor (es decir, mientras no se solicite su anulación, terminación, suspensión o el retiro del Estado), no existe ningún procedimiento o mecanismo por virtud del cual el Estado se pueda desligar de las obligaciones asumidas por su causa, lo que implica que, más allá de que dicho documento internacional vaya en contra de cualquiera de las normas internas o, incluso, de la propia Ley Fundamental, la nación está obligada a su cumplimiento y dicho acatamiento le puede ser exigido a través de cualquiera de los medios que el mismo derecho internacional público establece.

\footnotetext{
internacionales tenían la misma jerarquía normativa, esto es, justo el rango inmediato inferior a la Constitución; de tal forma que un tratado internacional no podía servir de criterio para determinar la constitucionalidad de una ley ni viceversa. Este criterio fue abandonado en el año de 1999 cuando la Suprema Corte de Justicia Mexicana, al resolver el amparo en revisión $1475 / 98$ promovido por el Sindicato Nacional de Controladores de Tránsito Aéreo, emitió una tesis aislada en la que dijo que los tratados internacionales se ubican jerárquicamente por encima de las leyes federales y en un segundo plano respecto de la Constitución. Empero, este criterio no resulta obligatorio y, hasta el día de hoy, tampoco ha sido reiterado en la solución de ningún otro juicio. Para mayor información sobre el tema ver: Guillermo I. Ortiz Mayagoitia, "Derecho Internacional y Derecho Constitucional: Un fallo interesante», en: Anuario de Derecho Constitucional Latinoamericano Edición 2000, KAS/CIEDLA, Buenos Aires 2000, pp. 529-539; y Eduardo Ferrer Mac-Gregor, "La Corte Interamericana de Derechos Humanos como Intérprete Constitucional (Dimensión Transnacional del Derecho Procesal Constitucional)", en: Derecho Procesal Constitucional, Porrúa, México 2001, p. 711.
} 
Estas premisas que de alguna manera son evidentes y hasta asequibles casi para cualquiera, suscitan no pocas complicaciones cuando se les aprecia en su funcionamiento ordinario, pues lo cierto es que, por un lado, en ocasiones los órganos internos de los Estados signatarios de un instrumento internacional no conocen la trascendencia de éstos ni la intromisión que implica para su propio orden jurídico y, además, porque los tribunales creados por estos tratados, al ir definiendo su competencia a través del conocimiento de procesos y la emisión de sentencias, han tomado cauces que muy probablemente nunca imaginaron los redactores de dichos documentos internacionales.

Para explicar estas nociones con más claridad nos referiremos a continuación a dos casos resueltos recientemente por la Corte Interamericana de Derechos Humanos.

\section{Los casos «Barrios Altos» $\mathrm{y}$ «La Última Tentación de Cristo»}

Recientemente la Corte Interamericana de Derechos Humanos resolvió un par de casos que sentaron sendos precedentes de fundamental importancia. Nos referimos a los casos conocidos como «La Última Tentación de Cristo" $\mathrm{y}$ "Barrios Altos".

El último de ellos, es decir, el caso "Barrios Altos", llamado así por ser éste el nombre con el que se conoce al vecindario limeño en donde se sucedieron flagrantes transgresiones a los derechos humanos por parte de un escuadrón de eliminación del ejército peruano llamado "Grupo Colina", se suscitó con motivo de la impugnación de que fueron objeto ante la Corte Interamericana de Derechos Humanos dos leyes peruanas emitidas bajo el "Gobierno de Emergencia y Reconstrucción Nacional" al mando del ahora expresidente Alberto Fujimori.

Estos ordenamientos, es decir, las leyes $\mathrm{N}^{\circ} 26479$ y $\mathrm{N}^{\circ} 26492$, tuvieron por objeto, por un lado, exonerar de responsabilidad a los militares, policías y también civiles que hubieran cometido, entre 1980 y 1995 , violaciones a los derechos humanos o participado en esas violaciones, y por el otro, neutralizar o de alguna manera detener las actuaciones de los tribunales peruanos sobre este particular.

Al cabo de un largo y controvertido procedimiento, y pese a que el Estado Peruano se allanó a la demanda, los Magistrados de la Corte Interamericana resolvieron que las referidas leyes $\mathrm{N}^{\circ} 26479$ y $\mathrm{N}^{\circ} 26492$ 
transgredían los artículos $4^{\circ}$ (derecho a la vida), $5^{\circ}$ (derecho a la integridad personal), $8^{\circ}$ (garantías judiciales) y $25^{\circ}$ (protección judicial) de la Convención Americana sobre Derechos Humanos, por lo que concluyeron señalando que dichas leyes «carecen de efectos jurídicos y no pueden seguir representando un obstáculo para la investigación de los hechos que constituyen este caso ni para la identificación y el castigo de los responsables, ni pueden tener igual o similar impacto respecto de otros casos de violación de los derechos consagrados en la Convención Americana acontecidos en el Perú».

A pesar del eufemismo utilizado por los jueces de la Corte Interamericana de Derechos Humanos, resulta por demás evidente que la declaración relativa a que dichas leyes «carecen de efectos jurídicos» implica, necesariamente, la nulidad de las mismas.

Es decir que la Corte Interamericana, al igual que lo hace cualquier tribunal constitucional, asumió una función de legislador negativo, y desde su ámbito internacional, anuló con efectos generales ambos ordenamientos.

Las consecuencias en el hermano país latinoamericano no se hicieron esperar. Poco después del fallo de la Corte comenzaron a dictarse numerosas órdenes de detención en contra de los responsables y a ejecutarse con prontitud aunque, vale decir, ello en cierta medida gracias a que el régimen político bajo el cual se habían dictado las referidas leyes, ya había cesado.

Pero lo que para nuestros efectos destaca en relación con esta sentencia es la facultad que de alguna manera ha asumido dicho tribunal internacional para declarar la nulidad con efectos generales de una ley nacional.

En el orden jurídico mexicano, las leyes sólo pueden emitirse o reformarse mediante el procedimiento que dispone el artículo $72^{\circ}$ constitucional, en el ámbito federal, y los correspondientes preceptos, en el orden local, y en igual medida, solamente la Suprema Corte de Justicia de la Nación, en su carácter de Tribunal Constitucional, está facultada para declarar la nulidad total o parcial de una ley. Igual o análogos sistemas rigen en la mayoría de las naciones.

Aunado a ello, la nulidad que puede declarar nuestro Máximo Tribunal, única y exclusivamente puede ser motivada por razones de orden constitucional, esto es, cuando la ley haya sido dictada sin atender al procedimiento de creación respectivo o cuando su contenido vaya en contra del texto de nuestra Norma Fundamental. 
Además, la sentencia que sobre el particular emita nuestra Suprema Corte de Justicia será, por el simple hecho de haberla emitido ella, inapelable, firme, ejecutoria, y ningún otro órgano colegiado o unipersonal de nuestro país podrá revocarla, puesto que goza del privilegio de convertirse automáticamente en cosa juzgada. Pero ¿podría un tribunal internacional revocar un fallo del Máximo Tribunal de una nación?

Veamos el segundo caso al que hicimos referencia desde un inicio; el denominado caso de "La Última Tentación de Cristo".

El artículo $19^{\circ}$, punto 12, de la Constitución Política de Chile establece un sistema de censura para la exhibición y publicidad de la producción cinematográfica. Con base en dicho precepto constitucional y en el Decreto Ley $\mathrm{N}^{\circ}$ 679, el Consejo de Calificación Cinematográfica chileno rechazó la exhibición en este país de la película «La Última Tentación de Cristo», previa petición que para tales efectos le formulase la empresa United International Pictures Ltda. Dicha compañía, en un intento por conseguir la exhibición de la película, recurrió la resolución del Consejo ante un tribunal de apelación, pero la resolución fue confirmada por este último.

Siete años después, ante una nueva petición de esta misma compañía norteamericana, el Consejo de Calificación Cinematográfica revisó su resolución y en esta ocasión, por mayoría de votos, autorizó la exhibición de la película para espectadores mayores de 18 años.

La resolución del Consejo nuevamente fue recurrida, pero esta vez por siete personas físicas "por y a nombre de Jesucristo, la Iglesia Católica y por sí mismos" ante la Corte de Apelaciones de Santiago, la que previo el trámite correspondiente, emitió su sentencia estimando el recurso de apelación promovido y dejando con ello sin efectos la resolución administrativa del Consejo de Calificación Cinematográfica, con lo cual, nuevamente quedó prohibida la exhibición del film.

Sin embargo, nuevamente diversas personas físicas interpusieron en contra de este último fallo una apelación ante la Corte Suprema de Justicia de Chile, esto es, la máxima autoridad judicial en ese país, la que de nueva cuenta confirmó la sentencia de la Corte de Apelaciones de Santiago y por ende, ratificó la prohibición para exhibir en Chile el referido film.

Cabe decir que si bien el entonces Presidente de Chile, Eduardo Frei, presentó un proyecto de reforma al artículo $19^{\circ}$, punto 12 , constitucional y que dicha iniciativa fue aprobada casi de inmediato por la Cámara 
de Diputados, hasta el momento no ha sido completado el proceso de reforma constitucional.

A este respecto la Corte Interamericana, previa la tramitación del procedimiento correspondiente, resolvió por unanimidad de votos que el Estado Chileno había violado el derecho a la libertad de pensamiento y expresión consagrados en el artículo $13^{\circ}$ de la Convención Americana sobre Derechos Humanos y que, por ende, debía modificar su ordenamiento jurídico interno en un plazo razonable, con el fin de suprimir la censura previa y permitir la exhibición de la película «La Última Tentación de Cristom.

Necesario resulta hacer notar en este punto que la modificación al derecho interno a que se refería la Corte Interamericana, concretamente aludía al Decreto Ley $\mathrm{N}^{\circ} 679$ y, muy especialmente, al artículo $19^{\circ}$, punto 12, de la Constitución Política de Chile. Es decir que por virtud de la sentencia de este tribunal constitucional, no sólo se revocó una sentencia ejecutoria del Máximo Tribunal chileno, sino que además, se obligó a la nación a reformar su texto constitucional.

Pero hay asimismo un punto en este fallo que destaca de manera fundamental: Si bien la Comisión Interamericana de Derechos Humanos (que es quien formalmente somete todos los asuntos a la jurisdicción de la Corte) había expresado en sus alegatos que «un acto contrario al derecho internacional producido por el Poder Judicial puede generar responsabilidad internacional del Estado siempre y cuando éste en su conjunto asuma los criterios dados por el Poder Judicial" y, en orden a ello, había solicitado a la Corte que declarase que Chile se encontraba «en un proceso para que [...] se adopten las medidas necesarias para eliminar la censura cinematográfica y permitir así la exhibición de la película", haciendo con ello alusión a la iniciativa de reforma constitucional al artículo $19^{\circ}$, punto 12 , promovida por el entones presidente Eduardo Frei y que, como se dijo, se encontraba ya en discusión ante el Poder Legislativo de dicha nación, el referido tribunal internacional sentenció lo siguiente: «Esta Corte entiende que la responsabilidad internacional del Estado puede generarse por actos u omisiones de cualquier poder u órgano de éste, independientemente de su jerarquía, que violen la Convención Americana. Es decir, todo acto u omisión, imputable al Estado, en violación de las normas del Derecho Internacional de los Derechos Humanos, compromete la responsabilidad internacional del Estado. En el caso ésta se generó en virtud de que el artículo $19^{\circ}$ núme- 
ro 12 de la Constitución establece la censura previa en la producción cinematográfica y, por lo tanto, determina los actos de los Poderes Ejecutivo, Legislativo y Judicial».

Como puede apreciarse, si bien es cierto que la Corte Interamericana de Derechos Humanos no dijo literalmente que revocaba la sentencia de la Corte Suprema de Justicia de Chile, lo cierto es que prácticamente la dejó sin efectos o, de alguna manera, pasó sobre ella y, además, claramente señaló que los actos u omisiones provenientes de cualquier autoridad nacional, sean de la jerarquía que sea y sin importar que hayan sido emitidos por un órgano de funciones esencialmente técnicas y apolítico como lo es un Tribunal Constitucional, pueden dar lugar a que el Estado incurra en responsabilidad internacional.

Todo esto tiene una gran importancia para todas las naciones pero, de manera muy particular, para aquéllas en las que rigen sistema jurídicos como el nuestro que todavía se encuentran estructurados bajo la idea de que no existe nada ni nadie por encima de la Corte Suprema y mucho menos de la Constitución.

\section{Conclusiones}

De todo lo expresado podemos concluir, en primer término, que pese a lo que señalen las normas internas de una nación y sin que obste para ello lo que al respecto ejecuten, establezcan o sentencien las autoridades nacionales, los tratados internacionales, y sobre todo aquéllos que se refieren a la protección de los derechos humanos, tienen una jerarquía superior a la Constitución de los Estados signatarios.

En esa medida, menester es reconocer que los jueces internos de cada nación signataria tienen obligación de conducirse como verdaderos jueces internacionales, interpretando y aplicando, de la misma forma en que lo haría un juez internacional, los tratados internacionales sobre derechos humanos.

A este respecto resulta particularmente importante señalar que en lo relativo a los derechos de la persona humana se han reconocido dos principios o reglas de actuación jurisdiccional: $1^{\circ}$ el Principio de Progresividad, conforme al cual un individuo puede invocar los derechos del ordenamiento jurídico que más le favorezca, sin importar si éste es nacional o internacional, y $2^{\circ}$ que en materia de derechos huma- 
nos nunca es válida la interpretación restrictiva, de tal forma que siempre deben interpretarse de la manera más favorable para la persona humana.

Queda de manifiesto, asimismo, que los tribunales protectores de los derechos humanos tienden a convertirse en verdaderos tribunales constitucionales internacionales, y no sólo la Corte Interamericana de Derechos Humanos a la cual se ha hecho aquí especial referencia, sino también la Corte de Justicia de las Comunidades Europeas de Luxemburgo y, desde luego, el Tribunal Europeo de Derechos Humanos de Estrasburgo ${ }^{14}$.

Sobre el particular, resulta interesante hacer notar cómo estos tribunales de alguna manera definen su propia competencia a través de sus fallos, y que por lo menos en lo que respecta a la Corte Interamericana, esta competencia ha tendido a dilatarse cada vez más.

Una forma a través de la cual se podría evitar toda la problemática que de alguna manera se deja ver en líneas anteriores respecto al enfrentamiento entre el derecho nacional y el internacional, es el llamado control previo de la constitucionalidad de los tratados internacionales mediante el cual, la máxima autoridad jurisdiccional de una nación juzga sobre la adecuación del instrumento internacional a las normas internas del Estado antes de que el tratado sea propalado, determinando así de antemano si éste contraviene o no alguna norma constituciona ${ }^{15}$.

Así, por ejemplo, en Colombia la Corte Constitucional determina a través de este procedimiento si existe un vicio superable o uno no superable. En el primer caso, dicha Corte emite un fallo provisional y el tratado regresa al órgano encargado de su celebración para su ajuste, retornando posteriormente a la propia Corte Constitucional para que ésta falle en definitiva si es posible su celebración o no. En el caso de que la Corte advierta un vicio no superable, emite una declaración inmedia-

14 Eduardo Ferrer Mac-Gregor, «Los Tribunales Constitucionales y la Suprema Corte de Justicia de México", en: Derecho Procesal Constitucional, op. cit., p. 67

15 Humberto Nogueira Alcalá, "Las Constituciones Latinoamericanas, los Tratados Internacionales y los Derechos Humanos", en: Anuario de Derecho Constitucional Latinoamericano Edición 2000, KAS/CIEDLA, Buenos Aires 2000, p. 174 ; y Eduardo Ferrer Mac-Gregor «La Corte Interamericana de Derechos Humanos como Intérprete Constitucional (Dimensión Transnacional del Derecho Procesal Constitucional)" en: op. cit. p. 713 . 
ta de inconstitucionalidad que puede ser total o únicamente parcial, y conforme a la cual no podrá ser celebrado dicho tratado si previamente no se modifica la norma constitucional.

Como sea, es ya un hecho que la protección internacional de los derechos humanos va más allá de la soberanía nacional. Es ésta una tendencia que cada vez se consolida con más fuerza y que, al día de hoy, es imposible de desconocer. 